\title{
DISCURSO POLÍTICO E RELAÇÕES INTERNACIONAIS: O ESTADO NOVO E O GOVERNO ROOSEVELT (1936-1945)
}

Carmen Silvia Aita*

As ambições dos jovens políticos gaúchos da geração de 1907, então colegas da Faculdade de Direito de Porto Alegre, e ainda sob a forte influência da tradição castilhista-borgista, ${ }^{1}$ conhecem a partir de 1930 a possibilidade de organizarem institucionalmente a busca de uma nova identidade nacional.

A política arcaica e quase obsoleta da República Velha com as suas sucessões presidenciais feitas de acordos estaduais viciados e fraude eleitoral, inviabilizando a sedimentação de partidos políticos nacionais com alguma representatividade, passa a dar lugar ao desejo de uma unidade política, fortemente inspirado pela ascensão dos regimes ditatoriais das novas nações européias.

Uma necessidade imperativa de executivo forte, o culto pela hierarquia, o mito do líder carismático, os símbolos da identidade nacionalista, e principalmente, a grandeza do Estado, fazem da primeira metade da década de trinta no Brasil o momento de preparação para transformar esta inquietação coletiva em uma atividade política real.

E esta equipe que, chegando ao poder através da Revolução de 30, passará a representar a nova oportunidade, constrói seus laços associati-

- Recém-Mestre PUCRS/FAPERGS.

1 Sobre este tema ver BERTOL, Silvana. "Quem faz caso de estudantes?": Um estudo da participação do bloco acadêmico castilhista. Trabalho de Dissertação de Mestrado, Porto Alegre: PUCRS, Mimeo., 1993.

Estudos Ibero-Americanos. PUCRS, v.XXI, n.2, p. 145-153, dezembro, 1995 
vos menos por compartilhar posturas político-ideológicas que por afinidades regionais e de identidades biográficas. Portanto, as características que trarão ao governo Vargas tal especificidade, principalmente até agosto de 1939, definirão um tipo de discurso político que institui uma forma de nacionalismo bem particular.

\section{O discurso político do Estado Novo e a sua representação nas relações exteriores}

As diferenças de toda a ordem entre os membros do alto escalão do governo getulista aparecerão constantemente nas múltiplas faces que assumirá a fala política da diplomacia brasileira ao longo do período do conflito mundial. Preso a divergências pessoais e estranhamentos ideológicos, Vargas nunca alcançará uma unanimidade frente aos seus diversos gabinetes, nos aspectos relativos ao discurso político diante das questões internacionais. $^{2}$

Não há uma linha de continuidade neste discurso do Estado Novo em torno das negociações com o Departamento de Estado ou com o Tesouro americanos, na maneira de uma definição estratégica refletida ou um pensamento ideológico uniforme. A atuação da diplomacia brasileira irá elaborar o sentido representativo da sua trajetória, seguindo um estilo sutil e oportunista, que irá variar segundo os interesses específicos da organização do Estado centralizador, interesses externos dos países em conflito, a pressão do panamericanismo coercitivo, as hostilidades internas entre os membros do governo Vargas, a atuação personalista de alguns políticos e as possibilidades de barganha que as circunstâncias assim oferecerem.

Logo, o alinhamento da política externa brasileira será conduzido pelas diretrizes adotadas no Rio de Janeiro e, apesar de todos os embates internos conflitantes, caberá certamente a Vargas a última palavra. Esta postura do presidente colocará, algumas vezes, os próprios diplomatas e representantes oficiais em situações constrangedoras, na medida em que profere um discurso que chega a desautorizá-los, ou ainda mesmo pelo despreparo de alguns destes para as funções credenciadas.

2 SEITENFUS, Ricardo Antônio Silva. O Brasil de Getúlio Vargas e a formação dos blocos na II Guerra Mundial. São Paulo: Nacional, 1985, p. 27-37. 
Acontece que exatamente estes variados acidentes diplomáticos permitirão uma distensão no controle rígido por parte do presidente, dando chance ao desempenho pessoal de grandes personalidades. Pois estas lacunas no discurso nacionalista de Vargas, produzidas pela falta de uma linguagem com domínio global das questōes internacionais, irão permitir a ascensão de figuras que darão uma sustentação relevante e até mesmo destacada na forma de construir o discurso político nas questões específicas dos problemas brasileiros frente à diplomacia americana.

A desenvoltura de 'homem do mundo', ${ }^{3}$ que faltava ao político Getúlio Vargas, sobrará largamente em Osvaldo Euclides de Souza Aranha. Esta familiaridade com a diplomacia tornou este amigo pessoal do presidente, o homem mais importante nas soluções dos impasses internacionais entre Brasil e Estados Unidos, principalmente durante os anos de 1938/42.

Aparentemente isolado pelas suas insistentes posturas aliadas ao discurso liberal democrata do governo Roosevelt, e por isso altamente impopular aos olhos dos generais nacionalistas brasileiros, Aranha desenvolve com um êxito considerável uma linguagem de relativa contemporização frente aos percalços do discurso político do Estado Novo.

$\mathrm{O}$ chanceler articula a representatividade brasileira em Washington, ${ }^{4}$ sob a vista do presidente, tentando demonstrar uma imagem de suposta expectativa positiva do governo Vargas para com os desgastados compromissos do panamericanismo, na intenção de barganhar uma condição de equilíbrio que lhe permita tirar proveito das contradições entre as forças beligerantes, mantendo assim um "neutralismo negociável".

3 NEVES DA FONTOURA, J. Memórias. Porto Alegre: Globo, 1963, v. II, p. 8-11.

4 Em 9 de março de 1938, Aranha é empossado no Ministério das Relaçôes Exteriores. Dedica-se a preparaçăo da VIII Conferência Panamericana, realizada em dezembro do mesmo ano em Lima. No ano seguinte, tem início a "Missão Aranha", que resultará na assinatura de tratados econômicos entre Brasil e EUA. Já em 1940, o chanceler coordena a II Reunião de Consulta dos Ministros das Relaçōes Exteriores do Continente, realizado em Havana. Em maio de 1941 Aranha e o entâo ministro da Fazenda, Souza Costa, assinam acordo com os EUA para compra de armamentos americanos. Presidindo a III Reunião de Consulta dos Ministros das Relações Exteriores do Continente, em janeiro de 1942, Aranha exerce forte influência sobre a ruptura do governo brasileiro com as naçōes do eixo. Em março do mesmo ano, Aranha preside a criação da Comissão de Defesa Nacional, sendo que em agosto o governo brasileiro se declara em "estado de guerra" contra a Alemanha e Itália. 
Esta oportunidade de expor tais interesses, articulando um sentido reivindicatório, estava fundada na imagem que o governo brasileiro demonstrava na sua fala política. O Estado Novo identificava no seu discurso a modernidade estrutural da sociedade com o exercício da soberania, e isto passava necessariamente pelo desenvolvimento industrial e por um reaparelhamento militar tecnologicamente avançado para as forças armadas. Desde os primeiros pronunciamentos de Vargas em torno do programa da Aliança Liberal (AL), e mesmo ao longo do governo provisório (1930-34), estará sempre presente no seu discurso o apelo a realização de uma política de industrialização, condicionada, por sua vez, à criação, de um complexo siderúrgico, onde a indústria de base permitiria ao país transformar o ferro e o aço.

Tornando-se quase uma questão pessoal para Vargas, que entendia a proposta de criação da siderurgia como "tarefa árdua", o presidente tratava-a como um "problema máximo, pode dizer-se, básico", pois só a sua implantação poderia trazer ao país a "abundância e a independência econômica" ${ }^{15}$ que a soberania nacional precisava.

De janeiro de 1930, anunciando a plataforma da AL, até janeiro de 1942, quando o Brasil suspende a neutralidade e alinha-se aos Estados Unidos, a implantação do complexo siderúrgico no Brasil será a referência constante presente em todas as tentativas de negociações internacionais. E não poderia ser diferente, visto que a economia brasileira entraria em colapso, caso os Estados Unidos suspendessem a ajuda e os fornecimentos de matérias como aço, celulose e principalmente o petróleo.

Vargas associará em seu discurso político a idéia de autonomia econômica como sinônimo de soberania nacional, legando ao Estado centralizado a responsabilidade pela criação das condições de possibilidade do desenvolvimento efetivo de toda a sociedade.

A fala política do presidente dividirá com os países periféricos europeus um anti-liberalismo social, fruto da exclusão colonialista, trazendo para seu discurso elementos de repúdio ao individualismo democrata: progresso econômico sem conflito de classes, eliminando o cidadão em troca dos direites aparentemente reconhecidos da classe trabalhadora emergente.

5 VARGAS, Getúlio. A Nova Política do Brasil. Rio de Janeiro: José Olympio, 1938. v. I, p. 100-3. Nesta coleçāo, com 10 volumes, está contida a maior parte das falas do presidente, entre 1930 e 1944. 
O Estado Novo, a partir da linguagem política, constrói sua identidade na idéia de nacionalismo como sinônimo de intervenção estatal na economia e na sociedade. Traz subjacente a essa fala um sentido de modernidade política que será traduzido por patriotismo de interesses, e que justifica, por sua vez, a centralização de todo o poder político no Estado através da execução de um programa autoritário extremamente complexo e elaborado.

Desta perspectiva surge o perfil do autoritarismo de 37: diferente do coronelismo regional, diferente do liberalismo republicano e também diferente do totalitarismo europeu. O discurso político assume então uma particularidade até aquele momento incomum, pois as práticas, os efeitos e a performance do Estado centralizado eram altamente modernas, enquanto que as suas figuras representativas estavam marcadas no peso da tradição autoritária das oligarquias regionais.

A publicidade das realizações do Estado Novo se tornou mais inovadora que as próprias conseqüências das suas inovações. O discurso intelectual cientificista, fundado na ordem social, foi construído com sofisticação, rendendo efeitos compensadores para o casamento da modernidade das idéias políticas com a tradição autoritária. O processo de autonomização do setor estatal foi tão exaustivamente complexificado que ultrapassou para muito além da cooptação dos diferentes grupos sociais, adquirindo movimento próprio e definindo mecanismos e atitudes que conheceram novos desdobramentos até então completamente diferentes às máquinas estatais regionais. Foi desenvolvida uma tecnoburocracia estatal que criou a centralização do processo decisório e favoreceu o esvaziamento do debate político, mantendo o âmbito das negociações nos estreitos limites dos grupos interessados.

A destruição do discurso da representação política inspirada no modelo democrático liberal aniquilaria os interesses regionais, ainda vinculados ao coronelismo, impondo o interesse público sobre o privado, e por conseguinte, o poder público sobre o poder privado, inviabilizando, por sua vez, formas autônomas de representatividade classista. O discurso político varguista propagava uma imagem contratual, i.e., tomava para si o poder privado do cidadão, e em troca lhe assegurava representatividade social. Esta construção da representação política garantia ao Estado Novo uma autonomia que libertava o governo central da interferência direta do poder privado de classes, grupos ou facções.

Além de aparecer como um momento novo, de representação do simbolismo político da nação, a necessidade de constituir este discurso 
significado de forma tradicionalmente autoritária, flagra os conflitos constitutivos do Estado brasileiro, com suas elites econômicas prematuras de força para sustentarem a modernidade industrial e a incapacidade das classes médias e trabalhadoras emergentes de assegurarem uma representatividade policlassista. ${ }^{6}$

Dentro da especificidade deste discurso, o exército assumiu um papel que transcenderia os seus limites enquanto corporação militar, pois seria um elo de fortalecimento deste mesmo discurso autoritário diante da fragilidade estrutural e da indisciplina da organização liberal da República Velha. Deste vínculo orgânico entre o Estado e as armas, procede inclusive a grande influência do alto comando militar nas questões internacionais. Somam-se a isto os laços de amizade de longa data entre os generais Pedro Aurélio de Góis Monteiro e Eurico Gaspar Dutra com Getúlio.

A conduta do discurso do Estado, embora construíndo uma especificidade muito sui generis no seu caráter moderno e autoritário, ao mesmo tempo que não contraditoriamente conservador, nem sempre estava de todo alheia aos problemas internos do próprio Estado americano. Vargas, através do contato constante com as embaixadas, tinha sob controle a situação dos EUA, nos aspectos referentes a sua política de bastidores, pois se faltava ao estadista uma maior desenvoltura nas questões diplomáticas, sobrava ao político habilidade, paciência e senso de oportunidade.

\section{A posição do Brasil diante do "Winte War" americano}

O Brasil, mesmo distante, acompanhava o momento em que foi implantada a economia de guerra, em dezembro de 1941. A esta época, Washington era o centro nervoso da América. O fascínio cosmopolita estava presente no discurso de Roosevelt, veiculado através das "conversas ao pé do rádio".

Apesar do apelo carismático do presidente americano, não havia muitas chances de abafar as acirradas lutas pelo poder entre fortes personalidades como Henry Wallace, vice-presidente, Cordell Hull,

6 Sobre a questão da construção interna do Estado Novo ver DINIZ, Eli. $O$ Estado Novo: estrutura de poder e relações de classe. In: Fausto, Bóris (org.). HGCB. São Paulo: Bertrand do Brasil, 1991, v. 10, cap. II, p. 78-120. 
secretário de Estado, Henry Morgenthau, do Tesouro e Jesse Jones, do Departamento de Comércio. Travava-se uma batalha interna ao longo de 1941, pois antes da entrada dos EUA na guerra, Cordell Hull hesitava em determinar um bloqueio dos bens do Eixo, se antagonizando, desta forma, com Morgenthau que, anterior ao ingresso dos EUA na guerra, desejava fortalecer a causa aliada pela imposição de bloqueios e controles a transações com a Alemanha e a Itália. Somente em abril de 41, quando a frente ocidental na Europa entrou em colapso, ficou vitorioso o ponto de vista do Tesouro.

E a partir de então o discurso político do departamento de Estado americano construiu a sua relação de dominação através da articulação da linguagem econômica, lançando mão dạ aparente oferta de "ajuda" aos países desfavorecidos em face ao conflito. Neste sentido a diplomacia americana foi sumamente ativista. Sucederam-se várias conferências econômicas que tinham por objetivo principal definir a nova política econômica do governo americano diante das potências aliadas. Em 1943, foi criada a UNRRA (United Natios Relief and Rehabilitation Agency). Tratava-se da instituição da grande organização encarregada de "socorro" e "reabilitação" dos países devastados pela guerra. O delegado brasileiro da conferência era o embaixador Sebastião Sampaio, que causou certos embaraços à delegação de seu país, visto que o Brasil se apresentava como doador eventual de café, e não caberia exercer papel muito expressivo. Denota-se daí, a essa época, um certo despreparo da diplomacia brasileira na sua representatividade internacional diante da individualidade política do discurso econômico dos EUA.

Esse problema não voltou a se repetir na conferência de Bretton Woods, realizada em julho de 1944. A delegação brasileira era agora presidida pelo ministro Souza Costa, acompanhado pelo prof. Eugênio Gudin e por Octávio de Gouvea Bulhões, chefe da Divisão de Estudos Econômicos e Financeiros do ministério da Fazenda. Acompanhavamna também Francisco Alves dos Santos Filho, diretor de câmbio do Banco do Brasil, e Victor Azevedo Bastian, diretor do Banco da Província do Rio Grande do Sul.

Neste momento a delegação brasileira, já devidamente instrumentalizada, soube representar-se por um discurso político que reivindicou oportunamente uma posição estratégica nas soluções das questões econômicas do país no quadro latino-americano.

A discussão mais significativa da conferência se colocava pela disputa entre os dois planos: o plano Keynes refletia os interesses da 
Inglaterra, em que pensava montar um mecanismo internacional capaz de assegurar liquidez ao sistema e evitar excessiva concentração de recursos nas mãos dos países credores (no caso os Estados Unidos). Aos americanos, ao contrário, interessava, através do plano White, manter a posição dominante da sua moeda, como o maior país credor que era no cenário mundial. Permaneceu vencedor o plano White. E a discussão final versava em torno do discurso dos países europeus, que exigiam do Banco Mundial absoluta prioridade no trabalho de reconstrução das zonas devastadas pela guerra, e do apelo dos países subdesenvolvidos, que arguíam que eram devastados pela pobreza, e que esta representava um tipo de devastação não menos cruel que a guerra.?

A conferência de Bretton Woods seria a última das grandes peças que construiria o sentido apropriado da linguagem da engenharia econômica montada durante a guerra. A partir das decisões entre as grandes potências que dela participaram (44 países estavam presentes com seus respectivos representantes), o departamento de Estado americano articulou, sob o pretexto do "Winte-War", um discurso político de dominação econômica para a América Latina.

Mas longe de conseguir alcançar alguma uniformidade nos ajustes internacionais, o panamericanismo se transformou em um pretexto formal para o governo americano negociar os seus interesses com interferências drásticas, tentando atenuar os tímidos avanços de poder político, que favoreciam, eventualmente, um relativo e limitado acesso dos países latinos.

O Governo dos Estados Unidos, lançando a estratégia da "interferência amigável", usaria o panamericanismo na tentativa de aniquilar as intenções de nacionalismos periféricos construírem os seus discursos de autonomia, idealizadamente inspirados na modernidade social das potências totalitárias ascendentes no cenário mundial.

Destas tentativas de negociações internacionais tumultuadas, surgiriam as diferentes respostas dos discursos políticos dos países latinoamericanos.

Situar a compreensão do discurso político do Estado Novo no panorama das relações internacionais exige necessariamente demonstrar

7 CAMPO5, Roberto. A lanterna na popa: memórias/Roberbo Campos. Rio de Janeiro: Topbooks, 1994. p. 62-71. A biografia do político, bastante erudita, interessante e polêmica, traz um capítulo dedicado ao desempenho da embaixada brasileira nos EUA durante a $2^{\text {a }}$. Guerra, trabalhando densamente a linguagem econômica do período. 
os mecanismos de alcance da diplomacia brasileira na tentativa de estabelecer uma postura diferenciada, que possibilitasse ao governo varguista algum poder de barganha nas negociações políticas da nova geografia econômica da América Latina.

Ao mesmo tempo, entender as oscilações da postura do Brasil nos mecanismos de dominação das relações internacionais, remete a complexidade do discurso do caso brasileiro e a sua especificidade, pois parece residir exatamente nestes espaços obscuros das relações de poder a pouca, mas essencial, oportunidade de negociação que o Brasil conquistou em meio a intransigência determinada do governo americano.

E a despeito das deficiências da diplomacia brasileira, da precariedade bélica e da condição periférica do Brasil no conflito, se produziu no Estado Novo uma outra maneira de representar o discurso político frente a dominação internacional. Neste contexto, a declaração de guerra ao Eixo, em 1942, foi um processo longamente negociado, com momentos de tensão e algum reconhecimento da posição do Brasil como uma virtual liderança no sul do continente. ${ }^{8}$

8 A análise do discurso político do Estado Novo nas Relaçōes Internacionais foi trabalhada a partir da pesquisa realizada na documentação do arquivo Getúlio Vargas (FGV), que contém correspondências, relatórios e discursos tanto do presidente Vargas quanto dos representantes das embaixadas brasileira e americana, compreendendo o período de 1936 a 1945. 